\title{
Regular Home Health Care Visits Reduce Health Expenditure Among Home Care Patients: A Retrospective Cohort Study in a Community Hospital in Northern Taiwan
}

\author{
Tzu-Jung Chou \\ National Taiwan University Hospital \\ Jen-Kuei Peng \\ National Taiwan University Hospital \\ You-Ling Chen \\ Center for Drug Evaluation \\ Hao-Hsiang Chang ( $\sim$ allanchanghs@gmail.com ) \\ National Taiwan University Hospital \\ Yi-Hsuan Lee \\ National Taiwan University Hospital Bei-Hu Branch \\ Kuo-Chin Huang \\ National Taiwan University Hospital Bei-Hu Branch
}

\section{Research Article}

Keywords: Community-based care, Home health care, Health expenditure, Long-term care

Posted Date: September 21st, 2021

DOl: https://doi.org/10.21203/rs.3.rs-898434/v1

License: (c) (i) This work is licensed under a Creative Commons Attribution 4.0 International License.

Read Full License 


\section{Abstract}

Background: In response to the rapidly aging population with anticipated growth of chronic disabling diseases, the National Health Insurance program in Taiwan has established home health care services since 1995. Medically and functionally compromised elders with multiple chronic conditions, tend to have increased need for home health care $(\mathrm{HHC})$ and higher medical costs. Our study aimed to identify health expenditure and its influencing factors among home care patients and to clarify whether regular $\mathrm{HHC}$ visits reduce health expenditure.

Methods: A retrospective observational cohort study on individuals receiving $\mathrm{HHC}$ was conducted at National Taiwan University Hospital Bei-Hu Branch from 2010 to 2015. Patients aged $<20$ years, did not receive $\mathrm{HHC}$ for at least 6 months, or did not receive regular hospital care at our healthcare system were excluded. The patient characteristics, health service utilization, and health expenditure were collected. Total health expenditure was defined as the sum of outpatient clinic, emergency department and hospitalization cost. Considering the distribution of costs data was highly skewed, a generalized linear model was applied to estimate the impact patient factors on healthcare expenditure.

Results: A total of 1,285 home care patients, mean age $79.4 \pm 12.9$ years and males $50.9 \%$, were enrolled. The majority (85\%) of the study population were totally dependent in daily activities with Barthel index 020 , and had Charlson comorbidity index score $\geq 4$. The median monthly total expenditure per person was US\$737 (IQR, 229-1,935), which broke down to US\$414 (IQR,56-1,234) for hospitalization, US\$170 (IQR,73-369) for outpatient clinic, and US\$60 (IQR, 9-150) for emergency department. Home care patients with higher need for nursing services utilization $(p<0.05)$, indwelling tracheostomy tube $(p<0.05)$, underlying neoplasm $(p<0.05)$, or registry of catastrophic illness certificate $(p<0.001)$, had higher health expenditure. On the other hand, regular $\mathrm{HHC}$ visits significantly lowered total health expenditure $(p<0.001)$.

Conclusions: Patient characteristics that incurred higher health expenditure were identified, whereas regular $\mathrm{HHC}$ visits have a potential role to reduce expenditure in the disabled homebound population. The visit number and frequency of $\mathrm{HHC}$ should be taken into account when making reimbursement policy in order to provide a sustainable and cost-effective HHC program.

\section{Background}

With a rapidly aging population and prolonged life expectancy, the incidence of chronic diseases, disability, and functional impairments has increased dramatically, which poses new challenges to our society's health care systems, social care, and health expenditure. ${ }^{1-3}$ Many elderly or community-dwelling individuals have high symptom burdens that make them difficult to get to the doctor's clinic and receive medical care. ${ }^{4,5}$ Home health care $(\mathrm{HHC})$ has therefore became important for these disabled homebound population. HHC represents a comprehensive, longitudinal care provided by a physician-supervised interdisciplinary team in the homes of patients. The provision of $\mathrm{HHC}$ has accelerated especially in the 
era of coronavirus disease 2019 (COVID-19) pandemic, because care at home can reduce the risk of exposure in the hospital and help capacity constraints in healthcare facilities. ${ }^{6}$ In addition, $\mathrm{HHC}$ services have been repeatedly shown to improve continuity of care, as well as reduce risk of readmission and mortality. 7,8

As the number of homebound individuals continue to rise, the demand for $\mathrm{HHC}$ also expands. ${ }^{9}$ In the United States, about 3.4 million Medicare fee-for-service beneficiaries received HHC in 2018, and the program spent $\$ 17.9$ billion on HHC services. ${ }^{10}$ Medicaid expenditures for home and community-based services have grown significantly, more than doubling from \$25.1 billion in 2002 to \$55 billion in $2012 .{ }^{11}$ How to establish a sustainable and cost-effective home health care program for homebound population has become even more critical.

Homebound individuals with multiple comorbidities or disabilities commensurately have increased healthcare utilization and higher health expenditure. ${ }^{12,13}$ In the US, the health expenditure among homebound Medicare beneficiaries with impaired function is twice as much as those similar beneficiaries with intact function. ${ }^{14}$ However, no consensus has been reached on the most effective way to provide $\mathrm{HHC}^{15,16}$ In part, the lack of consensus may be due to insufficient published literatures to determine the clinical impact and economic effect of HHC. ${ }^{17,18}$ Factors associated with health expenditure in the homebound population remain unclear. ${ }^{19}$ Given the implementation of the HHC emphasized value-based care, health providers need to create care models that produce good clinical results and prevent high-cost events.

This study aimed to identify the health expenditure and its influencing factors among home care patients and to clarify whether regular home health care visits reduce health expenditure. We identify which kind of chronic condition and patient characteristic incur higher health expenditure. Understanding factors contribute to health expenditure will help healthcare professionals and government develop strategic framework and provide effective HHC.

\section{Methods}

\section{Taiwan's National Health Insurance (NHI) Reimbursement of Home Health Care (HHC) Program}

The National Health Insurance (NHI) program in Taiwan has reimbursed HHC services since 1995, and the reimbursement includes physician or nurse visits, general nursing services, special skilled nursing services such as indwelling tube exchange and blood sampling. ${ }^{20}$ Enrollment criteria for the HHC program are focused on patients who meet one of the following conditions: (1) patients who are immobile and spends more than $50 \%$ of the time while awake either bed-bound or chair-bound; (2) patients who have a definite need for medical or nursing services; (3) chronic disease patients who require long-term nursing care or patients who need continual nursing care after being discharged from the hospital. If a physician assesses that a hospital patient qualifies for HHC, the patient will be referred to the hospital's home care department or transferred to another health care or nursing care institution. If 
the patient has not been hospitalized, but the physician finds he or she meets the conditions required for $\mathrm{HHC}$, the patient can apply directly for home health care with a health care or nursing care institution that has a home care department. The patients receiving $\mathrm{HHC}$ are categorized into 4 resource utilization groups (RUGs) according to the NHI reimbursement policy: RUG-1 is patients with $\mathrm{HHC}$ who need medical care or general nursing services only; RUG-2 to RUG-4 are groups of patients with HHC who need 1, 2, and more than 3 kinds of skilled nursing services, respectively. The NHI reimburses nursing visits with fixed rates according to RUGs, whereas physician visits in a fixed payment regardless of RUGs.

\section{Study design and setting}

This retrospective cohort study was conducted in the $\mathrm{HHC}$ unit a community hospital in northern Taiwan. Participants were eligible for $\mathrm{HHC}$ if they fit the enrollment criteria of $\mathrm{NHI}$ and resided within $10 \mathrm{~km}$ from the hospital. Study population was individuals enrolled in the HHC program from 2010 to 2015 . We collected the home visit records and baseline demographic data from the electronic medical records of our hospital. The outpatient department records, emergency department records, and hospitalization records were linked with the integrated healthcare information system of our hospital. Patients who did not receive regular hospital care at the healthcare system of our hospital were excluded. The regular hospital care referred to routine health check-up every 3 months at the clinic of our hospital or its branches. Patients aged $<20$ years and who did not receive $\mathrm{HHC}$ for at least 6 consecutive months were also excluded. The study flow diagram is shown in Fig. 1. The study was approved by the Institutional Review Board of National Taiwan University Hospital (NTUH-IRB-201606024RINC).

\section{Data collection}

We collected the following data for each patient based on the home health care records at the time of enrollment: age, sex, Charlson Comorbidity Index $(\mathrm{CCl})^{21}$, Barthel Index (BI) scores ${ }^{22}$, registry of catastrophic illness certificate, and indwelling tubes. Major diagnoses were identified by their medical records, coded according to the International Classification of Diseases, Tenth Revision, Clinical Modification (ICD-10-CM) codes. For further analysis, major diagnoses were thereafter categorized into 6 main homogeneous groups including cardiovascular disease, cerebrovascular disease, neurodegenerative disorder, neoplasm, diseases of genitourinary system, and others. In addition, patients with severe illnesses can apply for catastrophic illness certification under the $\mathrm{NHI}$ program, so as to be exempted from certain copayments when getting care for the illness or related conditions. Based on previous studies, patients certified with catastrophic illness had significantly more healthcare utilization and higher health expenditure, ${ }^{23,24}$ which was also an important variable to be considered.

As for health expenditure, the outpatient department (OPD) visits, emergency department (ED) visits, and hospitalizations expenditure were retrieved from the electronic medical records of the hospital integrated healthcare information system. ED visits that lead to hospitalizations were counted as both ED visits and hospitalizations. Health expenditures were analyzed using the perspective of the payer, in this case, the $\mathrm{NHI}$ program in Taiwan. The aggregate health expenditure for all individuals, including from the start of the program to the end of the study period or death of the individuals, were analyzed. Total health 
expenditure was defined as the sum of outpatient clinic, emergency department, and hospitalization expenditure. Currency was converted using the average exchange rate from 2010 to 2015 (1 US\$ = NTD 30.54). ${ }^{25}$

\section{Statistical analysis}

Baseline characteristics were presented as frequency for categorical variables, as mean $+/$ - standard deviation (SD) for normally distributed continuous variables, and as median (interquartile range, IQR) for continuous variables with skewed distributions. The Shapiro-Wilk test was used to test for normal distribution. Accordingly, median was compared using the Mann-Whitney test or the Kruskal-Wallis test. Considering the distribution of costs data was highly skewed, a generalized linear model (GLM) was applied to estimate the impact of patient factors on the healthcare expenditure, as recommended in previous research for health care cost data ${ }^{26}$. The marginal effects of the variables in USD were computed from the GLMs. A two-tailed $p$ value of $<0.05$ was considered statistically significant. All analyses were conducted using SPSS version 23.0 (SPSS INC, Chicago, IL, USA).

\section{Results}

\section{Patient characteristics}

A total of 1996 participants received HHC services at our hospital from 2010 to 2015 . Those who did not receive regular hospital care at our healthcare system were excluded $(n=245)$. We also excluded patients with age $<20$ years $(n=8)$ and length of stay in the program $<6$ months $(n=458)$. Finally, 1285 patients were enrolled in this study. The mean age $( \pm$ SD) was $79.4 \pm 12.9$ years, and 654 (50.9\%) patients were men. The median length of stay was 1.77 (IQR 1.07-3.02) years. $675(52.5 \%)$ of participants died during the follow-up period. The comorbidity burden was high in our study; $1088(84.7 \%)$ of the patients had CCl of 4 or greater. Most patients (84.8\%) were totally functionally dependent (BI scores of $0-20)$. Besides, most of the patients required at least one skilled nursing service, with 948 (73.8\%) RUG-2, 268 (20.9\%) RUG-3, and 25 (1.9\%) RUG-4. At the time of entering the program, 1244 (96.8\%) participants had more than or equal to one indwelling tubes, including 1008 (78.4\%) nasogastric (NG) tubes, 422 (32.8\%) Foley catheters, and 110 (8.6\%) tracheostomy tubes. Regarding major diagnosis, cardiovascular diseases appeared to be the most common comorbidity with a prevalence of $42 \%$, following cerebrovascular diseases $(18.7 \%)$ and neurodegenerative disorder (14\%). The characteristics of the study population were summarized in Table 1. 
Table 1

Basic Characteristics of the Study Population

\begin{tabular}{|c|c|}
\hline Characteristics & $N=1285$ \\
\hline Age in years, mean (SD) & $79.4(12.9)$ \\
\hline \multicolumn{2}{|l|}{ Age in group, $\mathrm{n}(\%)$} \\
\hline$<65$ & $131(10.2 \%)$ \\
\hline $65-74$ & $179(13.9 \%)$ \\
\hline $75-84$ & $490(38.1 \%)$ \\
\hline$\geq 85$ & $485(37.7 \%)$ \\
\hline \multicolumn{2}{|l|}{ Sex, n (\%) } \\
\hline Male & $654(50.9 \%)$ \\
\hline Female & $631(49.1 \%)$ \\
\hline \multicolumn{2}{|l|}{ CCl score, n (\%) } \\
\hline$\leq 3$ & $197(15.3 \%)$ \\
\hline$\geq 4$ & $1088(84.7 \%)$ \\
\hline \multicolumn{2}{|l|}{$\mathrm{BI}, \mathrm{n}(\%)$} \\
\hline$\geq 21-60$, moderate - severe dependent & $196(15.2 \%)$ \\
\hline $0-20$, totally dependent & $1089(84.8 \%)$ \\
\hline \multicolumn{2}{|l|}{ RUG, n (\%) } \\
\hline 1 & $44(3.4 \%)$ \\
\hline 2 & $948(73.8 \%)$ \\
\hline 3 & $268(20.9 \%)$ \\
\hline 4 & $25(1.9 \%)$ \\
\hline \multicolumn{2}{|l|}{ Indwelling tubes, $n(\%)$ * } \\
\hline NG tube & $1008(78.4 \%)$ \\
\hline Foley catheter & $422(32.8 \%)$ \\
\hline Tracheostomy tube & $110(8.6 \%)$ \\
\hline
\end{tabular}

\footnotetext{
* Patients may have more than one indwelling tube

$\mathrm{CCl}=$ Charlson Comorbidity Index $\mathrm{BI}=$ Barthel Index, $\mathrm{RUG}=$ resource utilization group, NG tube = nasogastric tube, $\mathrm{SD}=$ standard deviation
} 


\section{Characteristics}

Major diagnosis, n (\%)

Cardiovascular disease

Cerebrovascular disease

Neurodegenerative disorder

Neoplasm

Diseases of Genitourinary System

Others

Catastrophic illness, n (\%)

Yes

No

\section{$\mathrm{N}=1285$}

$540(42 \%)$

$240(18.7 \%)$

$180(14 \%)$

$120(9.3 \%)$

$60(4.7 \%)$

$145(11.3 \%)$

$391(30.4 \%)$

$894(69.6 \%)$

* Patients may have more than one indwelling tube

$\mathrm{CCl}=$ Charlson Comorbidity Index $\mathrm{BI}=$ Barthel Index, RUG = resource utilization group, NG tube = nasogastric tube, $\mathrm{SD}=$ standard deviation

\section{Health expenditures}

The median monthly total expenditure per person was US\$737 (IQR, 229-1,935), which broke down to US\$414 (IQR,56 - 1,234) for hospitalization, US\$170 (IQR,73-369) for OPD, and US\$60 (IQR, 9-150) for ED. We then analyzed the effect of pre-existing conditions and regular home health care visits on total health expenditure (Table 2). Age, $\mathrm{CCl}, \mathrm{BI}, \mathrm{RUG}$, indwelling tracheostomy tube, major diagnosis, registry of catastrophic illness, and home health care visits were significantly associated with health expenditure. We observed no significant differences between different groups based on patient sex. 
Table 2

Association between variable of interest and total health expenditure

\begin{tabular}{|c|c|c|}
\hline Variable & Median monthly cost (IQR) in USD & $p$ value \\
\hline Age & & $<0.001^{*}$ \\
\hline$<65$ & $1214.7(386.8-3640.5)$ & \\
\hline $65-74$ & $825.2(256.8-2439.9)$ & \\
\hline $75-84$ & $679.6(197.6-1686.3)$ & \\
\hline$\geq 85$ & $700.7(184.3-1604.7)$ & \\
\hline Gender & & 0.487 \\
\hline Male & $779.4(196.5-2130.1)$ & \\
\hline Female & $671.1(242.5-1687.0)$ & \\
\hline $\mathrm{CCl}$ & & $<0.001 *$ \\
\hline$\leq 3$ & $861.1(321.6-2655.6)$ & \\
\hline$\geq 4$ & $718.0(184.1-1731.9)$ & \\
\hline $\mathrm{BI}$ & & $0.009 *$ \\
\hline$\geq 21-60$, moderate - severe dependent & $824.3(315.8-2656.2)$ & \\
\hline $0-20$, totally dependent & $726.4(191.2-1727.5)$ & \\
\hline RUG & & $0.021^{\star}$ \\
\hline 1 & $582.0(173.3-1659.7)$ & \\
\hline 2 & $707.5(206.0-1742.0)$ & \\
\hline 3 & $948.4(307.7-2459.8)$ & \\
\hline 4 & $1686.2(147.3-2978.7)$ & \\
\hline \multicolumn{3}{|l|}{ Indwelling tubes } \\
\hline NG tube & $771.1(234.7-1875.6)$ & 0.851 \\
\hline Foley catheter & $648.0(130.7-1961.4)$ & 0.141 \\
\hline Tracheostomy tube & $1505.9(762.5-3446.1)$ & $<0.001^{*}$ \\
\hline
\end{tabular}

${ }^{*} p<0.05$

$\mathrm{CCl}=$ Charlson Comorbidity Index $\mathrm{BI}=$ Barthel Index, $\mathrm{RUG}=$ resource utilization group, $\mathrm{NG}$ tube = nasogastric tube 


\begin{tabular}{|lll|}
\hline Variable & Median monthly cost (IQR) in USD & $p$ value \\
\hline Major diagnosis & $656.6(174.7-1437.9)$ & $<0.001^{*}$ \\
Cardiovascular disease & $781.4(236.2-1931.0)$ & \\
Cerebrovascular disease & $381.7(91.3-1639.3)$ & \\
Neurodegenerative disorder & $2623.7(924.1-5114.5)$ & \\
Neoplasm & $775.9(1245.0-2172.4)$ & \\
Diseases of Genitourinary System & $737.0(298.8-1907.7)$ & $<0.001^{*}$ \\
Others & & \\
\hline Registry of catastrophic illness & $491.4(92.1-1183.0)$ & \\
No & $1932.4(735.3-3890.7)$ & \\
Yes & & \\
\hline Number of home health care visits & $1171.9(262.4-2938.5)$ & \\
$\leq 12 / y e a r$ & $548.7(200.2-1188.2)$ & \\
\hline$>12 / y e a r$ & & \\
\hline$* p<0.05$ & & \\
\hline CCI $=$ Charlson Comorbidity Index, BI = Barthel Index, RUG = resource utilization group, NG tube $=$ \\
nasogastric tube
\end{tabular}

In the generalized linear model, RUG-2 ( $p=0.029)$, RUG-3 $(p=0.003)$, indwelling tracheostomy tube ( $p=$ $0.025)$, major diagnosis of neoplasm $(p=0.027)$, and registry of catastrophic illness $(p<0.001)$ significantly increased health expenditure as shown in Table 3 . On the other hand, home care visits $>12$ times per year was significantly associated with lower health expenditure $(p<0.001)$. To evaluate the robustness of our results, we further evaluated the expenditure of ED, OPD, hospitalization in relation to regular home care visits. Home care visit $>12$ times per year had significantly lowered an average of US\$30.4 (34.06\%) on ED ( $p<0.001)$, US\$34.2 (16.62\%) on OPD ( $p=0.001)$, and US\$254.6 $(37.06 \%)$ on hospitalization $(p<0.001)$ expenditure (Fig. 2$)$. 
Table 3

Generalized linear models for factors associated with total health expenditure

\begin{tabular}{|c|c|c|}
\hline Variable & Monthly cost difference in USD & $p$ value \\
\hline \multicolumn{3}{|l|}{ Age } \\
\hline$<65$ & Reference & \\
\hline $65-74$ & -279.0 & 0.233 \\
\hline $75-84$ & -349.1 & 0.081 \\
\hline$\geq 85$ & -126.6 & 0.566 \\
\hline \multicolumn{3}{|l|}{$\mathrm{CCl}$} \\
\hline$\leq 3$ & Reference & \\
\hline$\geq 4$ & -611.7 & 0.548 \\
\hline \multicolumn{3}{|l|}{$\mathrm{Bl}$} \\
\hline$\geq 21-60$, moderate - severe dependent & Reference & \\
\hline $0-20$, totally dependent & 795.7 & 0.438 \\
\hline \multicolumn{3}{|l|}{ RUG } \\
\hline 1 & Reference & \\
\hline 2 & 549.4 & $0.029 *$ \\
\hline 3 & 928.4 & $0.003^{*}$ \\
\hline 4 & 886.1 & 0.060 \\
\hline \multicolumn{3}{|l|}{ Tracheostomy } \\
\hline No & Reference & \\
\hline Yes & 508.9 & $0.025^{\star}$ \\
\hline \multicolumn{3}{|l|}{ Major diagnosis, n (\%) } \\
\hline Cardiovascular disease & 11.9 & 0.948 \\
\hline Cerebrovascular disease & -36.7 & 0.855 \\
\hline Neurodegenerative disorder & -364.1 & 0.059 \\
\hline Neoplasm & 649.9 & $0.027^{\star}$ \\
\hline
\end{tabular}

* $p<0.05$

$\mathrm{CCl}=$ Charlson Comorbidity Index $\mathrm{BI}=$ Barthel Index, $\mathrm{RUG}=$ resource utilization group, $\mathrm{NG}$ tube = nasogastric tube 


\begin{tabular}{|lll|}
\hline Variable & Monthly cost difference in USD & $p$ value \\
\hline Diseases of Genitourinary System & 18.1 & 0.952 \\
\hline Others & Reference & \\
\hline Registry of catastrophic illness & & \\
\hline No & Reference & $<0.001^{*}$ \\
\hline Yes & 1660.7 & \\
\hline Number of home health care visits & & $<0.001^{*}$ \\
\hline$\leq 12 /$ year & Reference & \\
\hline$>12 /$ year & -1150.2 & \\
\hline$* p<0.05$ & & \\
\hline $\begin{array}{l}\text { CCI }=\text { Charlson Comorbidity Index, BI = Barthel Index, RUG = resource utilization group, NG tube }= \\
\text { nasogastric tube }\end{array}$ & \\
\hline
\end{tabular}

\section{Discussion}

Aging population with multiple comorbidities increased not only the need for $\mathrm{HHC}$ but also the economic burden on health expenditure. The $\mathrm{NHI}$ in Taiwan is on an unsustainable growth path in terms of health care expenditure and must get costs under control. ${ }^{27}$ Economic aspects should be an integral part of $\mathrm{HHC}$ in order to provide comprehensive, cost effective care and create sustainability. ${ }^{16}$ We thus conducted this retrospective cohort study to identify factors associated with health expenditure among HHC patients. The majority (85\%) of patients in our study had multiple chronic conditions with $\mathrm{CCl}$ of 4 or greater, and totally functionally dependent (BI scores of $0-20)$. The study population was vulnerable and dependent, which was similar to other home care studies in Taiwan and worldwide. ${ }^{5,8,28}$ Our study demonstrated that higher health expenditure was associated with the diagnosis of neoplasm, registry of catastrophic illness, indwelling tracheostomy tube, and requirement of higher need for skilled nursing services. On the other hand, regular HHC visits had the potential to reduce expenditure for ED, OPD, and hospitalization, as well as total health expenditure of home care patients.

In our study, we observed that the majority of health expenditure among home care patients is attributed to hospitalization. Regular HHC visits may contribute to the improvement of preventive intervention and the early response to initial phases of exacerbation, which minimize unnecessary hospitalizations and thereby reduce health expenditure. ${ }^{28,29}$ Previous studies have shown that $\mathrm{HHC}$ could reduce hospital admissions and health expenditure in individuals with heart failure ${ }^{30}$, chronic obstructive pulmonary disease $^{31}$, or any acute infection ${ }^{32,33}$. One study regarding disabled people who received HHC in Taiwan indicated that higher intensity of nursing visit (more than 12 times per year) was associated with a significant reduction in the risk of hospitalization and emergency services use; while higher intensity of 
physician visit (more than 6 times per year) was associated with fewer emergency services use. ${ }^{5}$ Worthy of note is that our study disclosed further information that regular home care visits have a potential role to reduce expenditure in these highly dependent population.

On the other hand, health expenditure was higher among patients with the diagnosis of neoplasm or registry of catastrophic illness certificate. For patients with high-cost serious illnesses, detailed care coordination by an interprofessional team, creation of a long-term relationship with patients and their family caregivers, and elicitation of patients' preferences are key elements in providing high quality of care. ${ }^{34}$ Since HHC providers not only understand the patients' diseases but also know their life directives, caregiver resources, and family situation, they can help them make the decisions that best align with the patients' preferences. For frail patients with serious illnesses, before disease entering terminal stage, goal of care should be discussed and early intervention of palliative management should be provided. ${ }^{35,36}$ When patients' condition worsen, $\mathrm{HHC}$ providers can deliver treatment plans that are concordant with patients' priorities, and avoid costly but futile treatments. ${ }^{37} \mathrm{~A}$ concurrent match cohort study published in 2018 had reported that savings of home-based primary care were mostly in end-of-life stage. ${ }^{17}$ Recognition of patient preferences should be enhanced in HHC providers, especially in patients' with underlying neoplasm or catastrophic illnesses.

Furthermore, long-term indwelling tubes may increase the risk of infection, patient morbidity, and mortality resulting in increased healthcare use and expenditure. ${ }^{38-40}$ The tube placement rate among $\mathrm{HHC}$ patients was high in our study. $96.8 \%$ of participants had at least one indwelling tubes. Previous studies disclosed that the prevalence of indwelling urinary catheters or nasogastric tube insertion among long-term care patients in Taiwan is higher than that in the United States or European countries. $39,41,42$ We found that indwelling tracheostomy tubes, as well as RUG-2 and RUG-3, were associated with higher health expenditure. Because the NHI in Taiwan reimburses home nursing visits at a fixed rate based on RUG classifications of patients, which is dependent on the number of skilled nursing services, this fee-forservice payment might result in the high rate of tube placement and the potentially inappropriate intubation of $\mathrm{HHC}$ patients. ${ }^{43,44}$ However, we believe that government should provide incentives for $\mathrm{HHC}$ providers to remove unnecessary indwelling tubes and proposes care provisions to prevent catheterassociated infection, in order to reduce health expenditure. ${ }^{45}$

Our study has several limitations. First of all, this is a single-center, retrospective cohort study. Although the size of study population included 1285 participants, the generalizability of these results to the nationwide or worldwide population may not be fully applicable. In addition, for those countries with social health insurance coverage of $\mathrm{HHC}$, the number of $\mathrm{HHC}$ visits should be taken into account when making reimbursement policy. Secondly, our data did not provide detailed socio-economic information such as family composition, caregiver status, polypharmacy and nutrition status, which precluded analysis of possible contributing factors. Furthermore, much development of new home care model including adoption of telemedicine has occurred in the past years, so further analysis with more recent 
data would be informative. Despite these limitations, our study findings still provide a better understanding of factors affecting health expenditure among home care patients.

\section{Conclusions}

Home care patients with higher need for nursing services utilization, indwelling tracheostomy tube, underlying neoplasm, or registry of catastrophic illness certificate, had higher health expenditure. Proactive, regular HHC visits can help reduce health expenditure, especially hospitalization. Our study results should be accounted for further cost analyses and in future reimbursement programs. Further studies investigating the appropriate intensity of home care visits by different disciplines to provide costeffective services are warranted.

\section{Abbreviations}

BI: Barthel Index; CCI: Charlson Comorbidity Index; COVID-19: coronavirus disease 2019; ED: emergency department; GLM: generalized linear model; HHC: Home health care; NG tubes: nasogastric tubes; NHI: National Health Insurance; IQR: interquartile range; OPD: outpatient department; RUGs: resource utilization groups; SD: standard deviation

\section{Declarations}

\section{Ethics approval and consent to participate:}

The study was approved by the Institutional Review Board of National Taiwan University Hospital under the protocol NTUH-IRB-201606024RINC. The study was considered exempt from consent because it was a secondary data analysis using de-identified data. The study was performed in accordance with the guidelines of the Declaration of Helsinki and Good Clinical Practice.

\section{Consent for publication:}

Not applicable.

\section{Availability of data and materials:}

The datasets used and/or analyzed during the current study are available from the corresponding author on reasonable request.

\section{Competing interests:}

The authors declare that they have no competing interests.

\section{Funding:}

This work was supported by Center for Drug Evaluation, Taiwan in the design of the study. 


\section{Authors' contributions:}

Conception and design the work: T-J C, J-K P, H-H C, K-C H. Analysis and interpretation of data: T-J C, J-K P, $\mathrm{H}-\mathrm{H} \mathrm{C}, \mathrm{K}-\mathrm{C} \mathrm{H}$. Writing the original draft: T-J C, Revised the manuscript: J-K P, Y-L C, H-H C, Y-H L, K-C H. All authors read and approved the final manuscript and have met the criteria for authorship.

\section{Acknowledgements:}

The authors sincerely thank the Department of Medical Research at National Taiwan University Hospital for helpful discussions during the manuscript preparation.

\section{References}

1. Ornstein, KA, Leff, B, Covinsky, KE, et al. Epidemiology of the Homebound Population in the United States. JAMA Internal Medicine 2015;175(7):1180-1186.

2. Li, C, Zhou, R, Yao, N, et al. Health Care Utilization and Unmet Needs in Chinese Older Adults With Multimorbidity and Functional Impairment. J Am Med Dir Assoc 2020.

3. Beard, JR, Officer, A, de Carvalho, IA, et al. The World report on ageing and health: a policy framework for healthy ageing. Lancet 2016;387(10033):2145-2154.

4. Qiu, WQ, Dean, M, Liu, T, et al. Physical and mental health of homebound older adults: an overlooked population. J Am Geriatr Soc 2010;58(12):2423-2428.

5. Lee, YH, Lu, CW, Huang, CT, et al. Impact of a home health care program for disabled patients in Taiwan: A nationwide population-based cohort study. Medicine (Baltimore) 2019;98(7):e14502.

6. Jones, $\mathrm{CD}$, Bowles, $\mathrm{KH}$. Emerging Challenges and Opportunities for Home Health Care in the Time of COVID-19. Journal of the American Medical Directors Association 2020;21(11):1517-1518.

7. Edes, T, Kinosian, B, Vuckovic, NH, et al. Better access, quality, and cost for clinically complex veterans with home-based primary care. J Am Geriatr Soc 2014;62(10):1954-1961.

8. Xiao, R, Miller, JA, Zafirau, WJ, et al. Impact of Home Health Care on Health Care Resource Utilization Following Hospital Discharge: A Cohort Study. The American Journal of Medicine 2018;131(4):395407.e335.

9. Ornstein, KA, Garrido, MM, Bollens-Lund, E, et al. Estimation of the Incident Homebound Population in the US Among Older Medicare Beneficiaries, 2012 to 2018. JAMA Internal Medicine 2020;180(7):1022-1025.

10. Report to Congress: Medicare payment policy; 2020. http://medpac.gov/docs/defaultsource/reports/mar20_entirereport_sec.pdf. Accessed 11/24 2020.

11. Caregiving in the United States 2020; 2020. https://doi.org/10.26419/ppi.00103.001. Accessed $11 / 242020$.

12. Eric De Jonge, $K$, Jamshed, $N$, Gilden, $D$, et al. Effects of Home-Based Primary Care on Medicare Costs in High-Risk Elders. Journal of the American Geriatrics Society 2014;62(10):1825-1831. 
13. Dieleman, JL, Squires, E, Bui, AL, et al. Factors Associated With Increases in US Health Care Spending, 1996-2013. JAMA 2017;318(17):1668-1678.

14. Johnston, KJ, Wen, $\mathrm{H}$, Hockenberry, JM, et al. Association Between Patient Cognitive and Functional Status and Medicare Total Annual Cost of Care: Implications for Value-Based Payment. JAMA Intern Med 2018;178(11):1489-1497.

15. Totten, AM, White-Chu, EF, Wasson, N, et al. AHRQ Comparative Effectiveness Reviews. In: HomeBased Primary Care Interventions. Rockville (MD): Agency for Healthcare Research and Quality (US), 2016.

16. Volpp, KG, Diamond, SM, Shrank, WH. Innovation in Home Care: Time for a New Payment Model. JAMA 2020;323(24):2474-2475.

17. Stanhope, SA, Cooley, MC, Ellington, LF, et al. The effects of home-based primary care on Medicare costs at Spectrum Health/Priority Health (Grand Rapids, MI, USA) from 2012-present: a matched cohort study. BMC Health Serv Res 2018;18(1):161.

18. Stall, N, Nowaczynski, M, Sinha, SK. Systematic review of outcomes from home-based primary care programs for homebound older adults. J Am Geriatr Soc 2014;62(12):2243-2251.

19. Kim, CO, Jang, SN. Home-Based Primary Care for Homebound Older Adults: Literature Review. Ann Geriatr Med Res 2018;22(2):62-72.

20. 2020-2021 Handbook of Taiwan's National Health Insurance.pdf. National Health Insurance Administration, Ministry of Health and Welfare, Taiwan; 2020.

21. Charlson, ME, Pompei, $\mathrm{P}, \mathrm{Ales}, \mathrm{KL}$, et al. A new method of classifying prognostic comorbidity in longitudinal studies: development and validation. Journal of chronic diseases 1987;40(5):373-383.

22. Mahoney, FI. Functional evaluation: the Barthel index. Md State Med J 1965;14:61-65.

23. Nan-Ping, Y, Yi-Hui, L, Chi-Yu, C, et al. Comparisons of medical utilizations and categorical diagnoses of emergency visits between the elderly with catastrophic illness certificates and those without. BMC Health Services Research 2013;13(1):152.

24. Wang, C, Cheng, S-F, Hung, J-L, et al. Highly frequent utilization of outpatient services in a national health insurance system - analysis of associated factors and underlying co-morbidity. Current Medical Research and Opinion 2020;36(11):1761-1767.

25. Institute of Economics, AS. New Taiwan Dollar to US Dollar Exchange Rate.; 2020. http://www.econ.sinica.edu.tw/content/economicdata/contents/2013090215155290268/? $M S I D=2013090914141961753 \& R=4$. Accessed November, 112020.

26. Mihaylova, B, Briggs, A, O'Hagan, A, et al. Review of statistical methods for analysing healthcare resources and costs. Health Economics 2011;20(8):897-916.

27. Owili, PO, Muga, MA, Yang, Y-T, et al. Perceived Impact of Taiwan's National Health Insurance Allocation Strategy: Health Professionals' Perspective. Int J Environ Res Public Health 2019;16(3):467. 
28. Vilà, A, Villegas, E, Cruanyes, J, et al. Cost-Effectiveness of a Barcelona Home Care Program for Individuals with Multimorbidity. Journal of the American Geriatrics Society 2015;63(5):1017-1024.

29. Health Quality, O. In-home care for optimizing chronic disease management in the community: an evidence-based analysis. Ontario health technology assessment series 2013;13(5):1-65.

30. Fergenbaum, J, Bermingham, S, Krahn, M, et al. Care in the Home for the Management of Chronic Heart Failure: Systematic Review and Cost-Effectiveness Analysis. Journal of Cardiovascular Nursing 2015;30(4S):S44-S51.

31. Bourbeau, J, Granados, D, Roze, S, et al. Cost-effectiveness of the COPD Patient Management European Trial home-based disease management program. International journal of chronic obstructive pulmonary disease 2019;14:645-657.

32. Levine, DM, Ouchi, K, Blanchfield, B, et al. Hospital-Level Care at Home for Acutely III Adults. Annals of Internal Medicine 2019;172(2):77-85.

33. Cryer, L, Shannon, SB, Van Amsterdam, M, et al. Costs For 'Hospital At Home' Patients Were 19 Percent Lower, With Equal Or Better Outcomes Compared To Similar Inpatients. Health Affairs 2012;31(6):1237-1243.

34. De Jonge, KE, Jamshed, N, Gilden, D, et al. Effects of home-based primary care on Medicare costs in high-risk elders. J Am Geriatr Soc 2014;62(10):1825-1831.

35. Brian Cassel, J, Kerr, KM, McClish, DK, et al. Effect of a Home-Based Palliative Care Program on Healthcare Use and Costs. Journal of the American Geriatrics Society 2016;64(11):2288-2295.

36. Gomes, B, Calanzani, N, Curiale, V, et al. Effectiveness and cost-effectiveness of home palliative care services for adults with advanced illness and their caregivers. Cochrane Database of Systematic Reviews 2013;(6).

37. Celso, BG, Meenrajan, S. The Triad That Matters: Palliative Medicine, Code Status, and Health Care Costs. American Journal of Hospice and Palliative Medicine® 2010;27(6):398-401.

38. Nonoyama, ML, McKim, DA, Road, J, et al. Healthcare utilisation and costs of home mechanical ventilation. Thorax 2018;73(7):644-651.

39. Mody, L, Krein, SL, Saint, S, et al. A Targeted Infection Prevention Intervention in Nursing Home Residents With Indwelling Devices: A Randomized Clinical Trial. JAMA Internal Medicine 2015;175(5):714-723.

40. Hutton, DW, Krein, SL, Saint, S, et al. Economic Evaluation of a Catheter-Associated Urinary Tract Infection Prevention Program in Nursing Homes. Journal of the American Geriatrics Society 2018;66(4):742-747.

41. Lin, C-S, Jao, F-C, Shin, P-W, et al. Evaluating the potential of removing long-term urinary catheters among home care recipients in Taiwan. Journal of Clinical Gerontology and Geriatrics 2011;2(4):105108.

42. Forde, L, Barry, F. Point prevalence survey of indwelling urinary catheter use and appropriateness in patients living at home and receiving a community nursing service in Ireland. Journal of Infection Prevention 2017;19(3):123-129. 
43. Chen, $\mathrm{Y}-\mathrm{T}$, Lin, $\mathrm{M}-\mathrm{H}$, Lai, $\mathrm{H}-\mathrm{Y}$, et al. Potentially inappropriate urinary catheter indwelling among longterm care facilities residents. Journal of Evaluation in Clinical Practice 2009;15(4):592-594.

44. Chang, $\mathrm{H}-\mathrm{T}$, Lai, $\mathrm{H}-\mathrm{Y}, \mathrm{Hwang}, \mathrm{IH}$, et al. Home healthcare services in Taiwan: a nationwide study among the older population. BMC Health Services Research 2010;10(1):274.

45. Using Behavioral Economics to Design Physician Incentives That Deliver High-Value Care. Annals of Internal Medicine 2016;164(2):114-119.

\section{Figures}

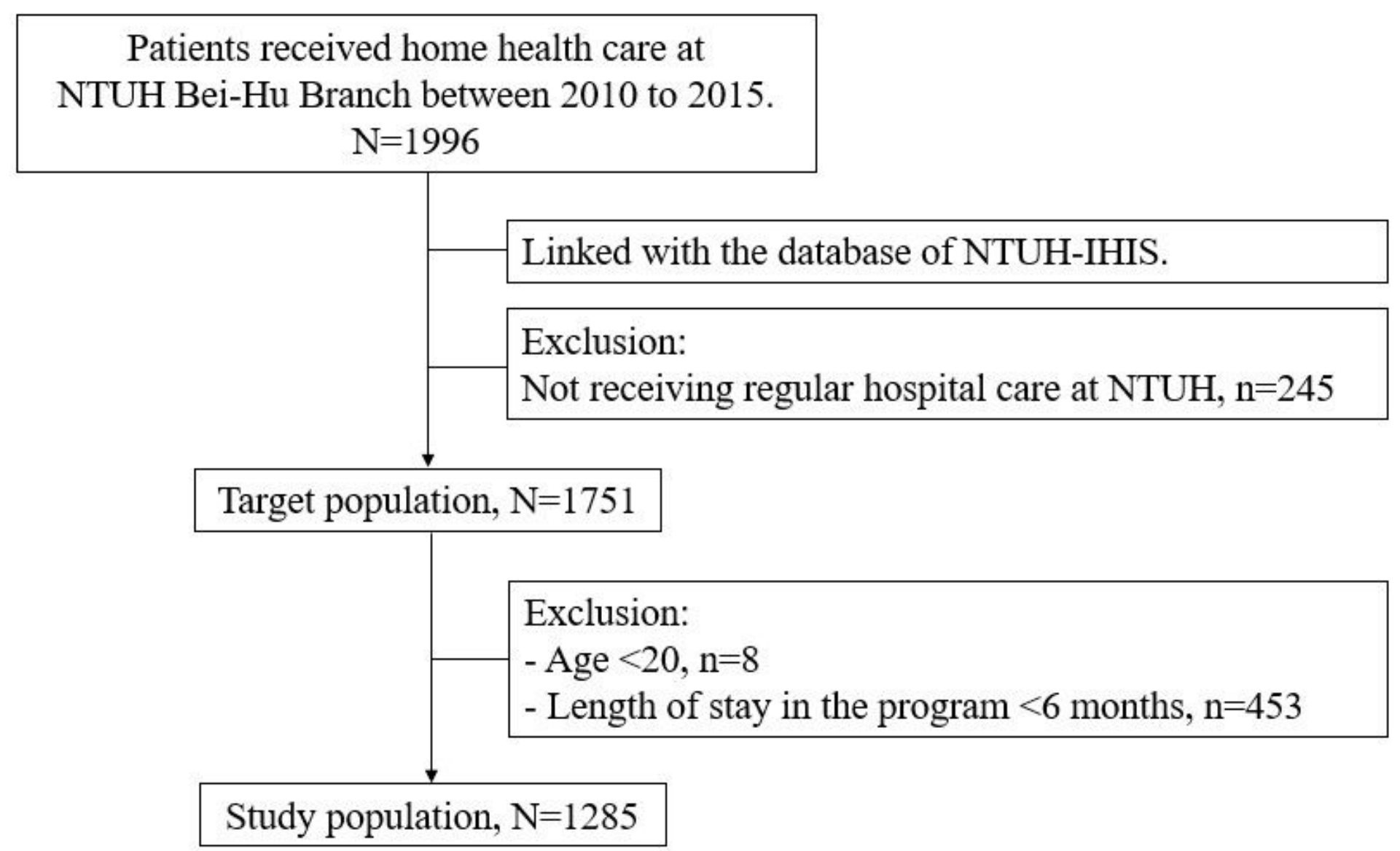

NTUH: National Taiwan University Hospital,

NTUH-IHIS: National Taiwan University Hospital integrated healthcare information system

\section{Figure 1}

Study flowchart. NTUH: National Taiwan University Hospital, NTUH-IHIS: National Taiwan University Hospital integrated healthcare information system 

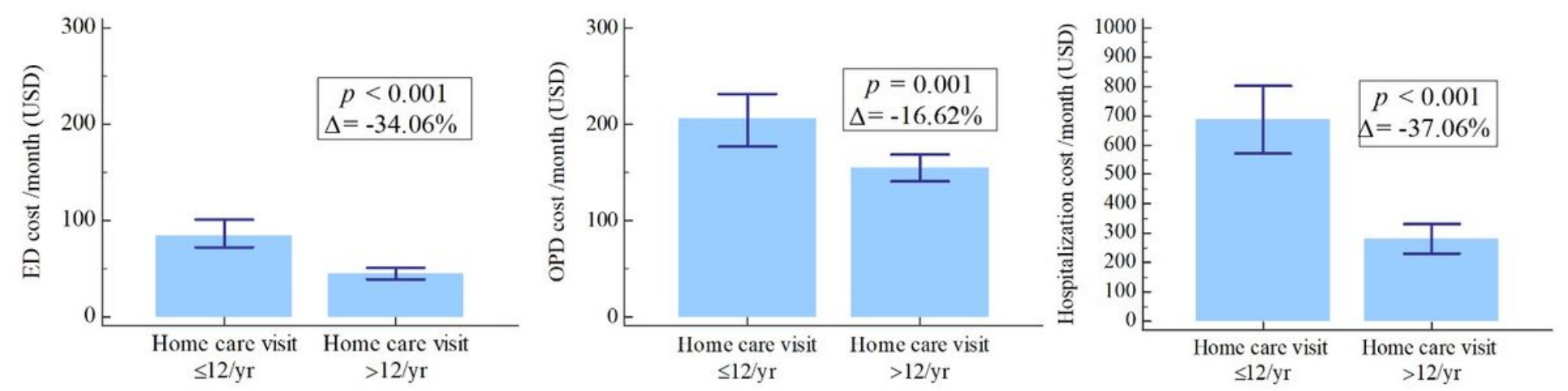

Figure 2

Comparison of health expenditure in relation to regular home care visits. ED: emergency department, OPD: outpatient department, USD: US dollar 